\title{
Navigating Changing Cultural Landscapes: A Quest for Identity and Belonging among Migrant Adolescents in Pietermaritzburg, South Africa
}

\section{Buhle Mpofu \\ ORCID iD: https://orcid.org/0000000268330810}

\begin{abstract}
The United Nations estimated in 2016 that there were about 244 million international migrants and 740 million internally displaced (intra-national) people, including children (UN 2016). Despite these substantial numbers, child and youth migration - although closely connected to injustices such as xenophobia, poverty, exploitation, social discrimination, and human trafficking - this has received little scholarly attention in Africa. This article first highlights the different approaches and a range of disciplinary perspectives, objectives, methods and theoretical underpinnings which characterise the discipline of children and youth migration studies and then draws from participatory observations as an embedded case study to explore the identity navigation experiences of five young migrants, two of them (Lisa and Joshua) ${ }^{1}$ engaged, through symbols/artefacts of cultural development for migrant children and youth in their quest for identity and belonging in new communities. In the last section, the paper employs the bi-acculturation theory to highlight formation processes for migrant adolescents as embodied in fashion and hairstyling practices, language/accent/naming, food cultures, and religious association and music. The article concludes that these symbolic
\end{abstract}

\footnotetext{
${ }^{1}$ These are not their real names. I have ensured anonymity of personal names and places to ensure confidentiality and protect subjects in this study. According to Oliver (2003), anonymity is commonly viewed as akin to the principle of privacy which is integral to the belief that individuals have the right to privacy.
} 


\section{Buhle Mpofu}

practices are intricately interwoven with the lived experiences of young migrants, and their quest for identity and belonging in South Africa.

Keywords: migrants, adolescents, acculturation, identity, belonging, Pietermaritzburg, South Africa

\section{Introduction}

The risks associated with child migration were recently thrust into the spotlight on Monday 24th June 2019 when the world woke up to a disturbing photographic image taken by Julia Le Duc ${ }^{2}$ showing the lifeless bodies of 26year-old Salvadoran migrant, Oscar Alberto Martinez Ramirez and his twoyear-old daughter, Valeria held tightly to his shirt as they attempted to cross the Rio Grande (The Guardian 25 June 2019). Circulation of the photo of Martinez with his daughter and their devastating death raised concerns about the experiences of migrants and refugees seeking safety in North America and Europe in particular. This incident highlighted how the children of migrants are directly affected by the experiences of their parents. It was reminiscent of the 2015 photograph of Alan Kurdi, the three-year-old Syrian toddler ${ }^{3}$ whose lifeless body was found on the shores of the sea in Greece. Both images were simultaneously devastating and provocative, insofar as they served as a call for political leaders to reconsider their policies towards the plight of migrants and refugees. Globally, migration studies (IOM 2010) indicate that children are significantly affected by migration through a number of factors:

... including psycho-social difficulties such as feelings of abandonment, low self-esteem, anger, depression and/or material obsession that could result in behaviour problems. School performance drops and some children even lose the right to education, lack access to

${ }^{2}$ The Guardian, Available on: https://www.theguardian.com/usnews/2019/jun/25/they-wanted-the-american-dream-reporter-reveals-storybehind-tragic-photo (Accessed on 27 June 2019.)

${ }^{3}$ More details and the photo can be seen on: https://www.theguardian.com/world/2015/sep/02/shocking-image-ofdrowned-syrian-boy-shows-tragic-plight-of-refugees (Accessed on 27 June 2019.) 
health care as some migrants do not have the ability to register newborns - these are some noticeable effects of migration on children who are sometimes vulnerable to sexual abuse and exploitation (IOM 2010:10).

The issue of unaccompanied or accompanied minors has been fairly well researched in Southern Africa, where we have seen increasing devastation of forced migration (Sloth-Nielsen \& Ackermann 2016; Palmary 2009). In an effort to contribute to the growing body of literature, this article draws on the experiences of Lisa, Joshua and three other young migrants to explore symbolic practices which inform identity formation for migrant children and youth in Pietermaritzburg, South Africa. Although participants in this study have not been exposed to dangers highlighted above, their experiences reflect the many dangers and different forms of alienation, xenophobia, cultural dislocation, exploitation, social discrimination and loss of identity to which migrants are exposed Global Migration Group (GMG 2013: 10).

In her now celebrated 2014 novel, Americanah, Nigerian novelist Adichie Chimamanda highlights intersecting themes on migration, race and identity that young migrants face. Drawing from her African background, the novel meticulously weaves together the racial, cultural and identity challenges experienced by migrant families, and particularly pays attention to the struggles of children and youth to demonstrate not just their strengthbut also the perils of navigating new cultural landscapes in an increasingly hostile American context. Chimamanda's readers will recognize that one character, Ifemelu's father speaks differently than other Nigerians in the book, peppering his speech liberally with some academic words because he feels ashamed that he did not obtain higher education like other Nigerians in the story who speak a mix of Nigerian 'standard English' and Nigerian Pidgin, languages based on English but distinctly Nigerian in their grammar and vocabulary. Once Ifemelu moved to America, she had to choose whether to speak with an American accent or not, which she did until she felt embarrassed and switched back to speaking with the Nigerian accent she learned at school.

Adichie Chimamanda (2014) uses language, accents, hair, dressing, food, names and nicknames as symbols to highlight socio-cultural differences between locals and those of the African diaspora. As they have to attend school in the new cities, migrant children and youth have to consciously and unconsciously navigate cultural barriers through negotiating new socio-cultural 


\section{Buhle Mpofu}

terrains cutting across languages, foods and dressing styles. To do this, they will require 'other components of cultural capital, namely skills, competency, and the new personal qualities' (Dang 2016: 170). These components of culture were observed by Toppelberg and Collins (2010) in their study on Language, Culture, and Adaptation in Immigrant Children as they found that specific aspects of the dual language development of immigrant children are highly relevant to their mental health and adaptation.

This article is based on a series of engagements with five young migrants in July 2019. In addition to observations, parental/guardian consent was also sought for interviews and permission was granted for the use of information collected from a formal counselling and blessing of a marriage service conducted in July 2019. Joshua - a male Cameroonian migrant youth who grew up in Pietermaritzburg and his parents had since returned to Cameroon - approached the leadership of a local protestant congregation to ask for a marriage proposal blessing to Lisa, who is a daughter of a Cameroonian Professor currently resident in Pietermaritzburg. Both were offered employment in Japan starting on the $1^{\text {st }}$ August 2019 and they were preparing to relocate. The other three young migrants, Nokubonga (Zimbabwean), Tasha (South African) and Ruth (Ghanaian), worship with their families in separate congregations and were known to the researcher as 'friends of the family'. Like Joshua and Lisa, Nokubonga and Tasha grew up in Pietermaritzburg but Ruth had lived in Johannesburg for most of her teenage years.

\section{Children and Young People in Migration Studies}

Research on children and migration is hardly a unified field and has been approached from a range of disciplinary perspectives characterised by different objectives, methods and theoretical underpinnings (Huijsmans 2015: 3). First, there are scholars whose work focuses on children affected by the migration of parents without having to migrate themselves, and these children are often referred to as 'left-behind children', as reflected in the work of Battistella and Conaco (1998), Asis (2006), Graham and Jordan (2011). Some studies have examined the narratives of childhood migration to shed light on how the family migration ethos, related to a wider societal culture of migration, and highlight themes of national identity and belonging (Trew 2009). To be a migrant family living in one country while one has close family members in another country 
can be 'confusing' to adolescents whose lives are in transition. As a result, literature which focuses on 'left-behind children' is largely informed by development psychology and is concerned with the emotional, psychological, cognitive, and physical effects of growing up with parent(s) living and working elsewhere (Huijsmans 2015: 3). In a paper titled Parental Absence as consequence of migration: reviewing literature, Mala Jokhan also observes that:

...parental migrations is not uncommon, as several parents may leave in order to economically improve their families' living standards, especially that of their dependent children. For these children, such experiences may adversely affect them, especially if they are left in vulnerable situations, as not all are fortunate enough to receive effective substitute parental care and guidance (Jokhan 2008: 1).

In Southern Africa this phenomenon is common but there are no records which show how many children are left behind by migrating parents, and this is compounded by the rise in child headed households as a result of orphaned children (caused by disease or other factors). Fillippa et al. (2013: 37) observed that deciding whether to leave children in their home country can be a voluntary or unavoidable choice for migrating parents and at times parents have to make this difficult choice because the remittances of migrant workers can potentially provide the children with a better lifestyle. In Southern Africa, migration to South Africa, Botswana and Europe, is common (Tawodzera \& Themane 2019) and most children are left in the care of the extended family or relatives who may not provide them with adequate care and as a result, these children may become vulnerable or end up migrating in search of their parents and better living conditions.

Children as migrants constitute the second scholarly focus on adolescent migration, with this group usually referred to as 'unaccompanied minors'; these migrants are younger than 18 years as defined and reflected in the work of Bhabha and Schmidt (2008). According to Huijmans (2015: 3), this body of work is divided between research on children who have migrated with families and those that migrate without their families (Yaqub 2009). In the South African context, stories of child migration have flourished alongside migrant narratives but there is currently limited literature on this phenomenon, despite growing concerns about child trafficking in the region. According to a 


\section{Buhle Mpofu}

report by the Policy Action Network (PAN) (2014) for example, the exact number of unaccompanied foreign migrant children in South Africa is unknown, due to the lack of proper registration and tracking systems. Consequently, most young migrants risk being sexually exploited. This is common for young girls and women who find themselves in situations where survival requires exchanging sexual activities for resources and services during migration or settlement in host communities (Idemudia et al. 2013).

A significant amount of the literature on children as migrants also focuses on measuring their mental health aspects and behavioural characteristics, comparing them with a host group (Diler et al. 2003). These behavioural experiences may include unsettling, as well as psychologically, socially, and religiously disconcerting encounters, which are often confusing to adolescents (Diler et al. 2003). Other scholars like Saria Shah (2004) are concerned with the confusion regarding the cultural expectations of parents on their migrant children and their identity in the host countries, and she asks: 'how do people learn the history of their group and culture when the group is spread around the world? Can rituals, memories and stories replace a physical community?' For Zudidah et al. (2013), children of immigrants - especially adolescents - face conflicting social contexts in which they attempt to incorporate 'here' and 'there' into a meaningful sense of self as they undergo the continuous process of constructing and re-constructing their identity. Elsewhere, examining the experiences of migrant children as they settle in host communities, Palmary (2009) paid attention to international law and the protection of children's rights through her work, For better implementation of Children's rights in South Africa; and highlights the plight of migrant children in Southern Africa by drawing attention to their rights within the United Nations Framework. This report gives an overview of the situation of children affected by migration into South Africa and pays particular attention to cross-border minors without adult caregivers. By contributing to literature on adolescent migrations, this embedded case study focuses on young migrants and their symbolic practices as identity formation and acculturation.

The bicultural acculturation approach (Arel 2014) has been employed as a conceptual framework for this study and undergirds ongoing identity formation processes as hybridity for emerging identities for immigrants who exchange values with each other, host communities and the global networks while drawing from their heritage cultures in home countries. According to Sari Arel (2014), bicultural acculturation is a process of maintaining a 
meaningful connection to a heritage culture while learning to manoeuvre in the host culture. This approach is considered optimal by immigrants - as opposed to early immigration ideology which maintained that full assimilation into society was the best option. However, other models of immigrant acculturation do not require the complete rejection of the heritage culture - but suggest that abandoning the heritage culture is associated with stress and they resort to a bicultural pathway in which immigrants simultaneously integrate into the host culture while maintaining their heritage culture. Empirical research supports the notion that people can hold more than one cultural framework in their minds, and that these frameworks influence their cognitions and behaviours for individuals who have internalised two cultures and are able to switch between the frameworks depending on the context (Hong et al. 2000).

\section{A Case study: Young Migrants and Symbolic Acculturation Practices}

According to Yin (2003:7), an embedded case study is a study containing more than one sub-unit of analysis and a case study is preferred in examining contemporary events when the relevant behaviours cannot be manipulated. This method is relevant for examining the lives of children and youth because, often, parents and care givers want to regulate their lives and as a result, manipulate their circumstances to fit into their expected norms. Given these possible manipulations and my status as a father who has two daughters (aged 9 and 13 years), the embedded case study approach controlled for boundaries between the phenomenon and context where the lines can become blurred. As Scholz and Tietje (2002) also observed, this methodology provides means of integrating quantitative and qualitative methods into a single research study and the exploration of sub-units of analysis provides for a detailed level of inquiry making the embedded case study method appropriate for descriptive and investigative empirical studies aimed at describing the features, context, and process of a phenomenon. Roland Scholz and Binder (2011) further elaborate, 'case is faceted or embedded in a conceptual grid' which allows for identification of key components of human and environmental systems (Scholz $\&$ Binder 2011: 25) and gives room for a participant-observer approach, and reliance on multiple sources of evidence through triangulation, and combining of information sources and artefacts. 


\section{Buhle Mpofu}

The motivation to do this short study was based on my relationship with the participants after counselling sessions and the other three are children of family friends living in the same community with the author ${ }^{4}$. The study was informed by the question: How do children of migrants navigate cultural landscapes to create new identities in their quest to belong in South African communities? As already explained, the case study utilised a qualitative approach to gain insights into the lived experiences of five young people (two of them [Lisa and Joshua] as a case study) with a view to explore how young migrants navigate cultural diversity through symbols/artefacts of identity formation in their quest for identity and belonging in Pietermaritzburg. This data was triangulated with information from interviews with three other youth on $26^{\text {th }}$ and $27^{\text {th }}$ July 2019 . One-on-one interviews with the three participants aged 13 to 18 years were conducted and procedures such as explaining the purpose of the interviews, ensuring confidentiality and seeking permission from parents/guardians were followed.

Starting with how I came to conduct a counselling session with one young couple, Lisa and Joshua, I was invited by the local elders at the request of the family, to provide counselling and bless their marriage before they relocated to Japan in August. During their last worship service, Joshua gave a farewell speech and explained the circumstances that led to their change of plan in their marriage arrangements:

My mom is visiting us from Cameroon. Some of you will know that yesterday our families had a small get together to ask God for a blessing in our marriage because we have changed our plans so that we marry before we go to Japan. We both got jobs as English instructors and decided to go and get married at the Cameroonian Embassy in Pretoria before we leave in two weeks' time (Joshua, addressing a congregation, 21 July 2019).

Lisa and Joshua had been dating for four years and preparations were already underway for them to get married in December, but they had to abruptly change their plans owing to the unexpected opportunity for

\footnotetext{
${ }^{4}$ As a researcher now a permanent resident, I migrated to South Africa is 2007 and have experienced some of the challenges highlighted here within the family.
} 
employment overseas. Joshua and Lisa were both the children of Cameroonian academics who met in Pietermaritzburg over a decade ago. Ironically, Joshua was raised by Lisa's parents after his family moved back to Cameroon and that is how he met his prospective wife. Lisa Although the proposal came as a surprise to their parents, the two families were happy to bless the marriage and took it as an opportunity to strengthen their cultural family ties. So, I was invited to bless the marriage before they travelled to Pretoria to be legally married at the Cameroonian Embassy ${ }^{5}$. The event was marked by Cameroonian-themed celebrations consisting of matching African attire, traditional food, music and dancing. According to Dang (2016), these elements marking the event and the cultural creativity constitute 'other components of cultural capital, namely skills, competency, and the new personal qualities' (2016: 170).

After moving to the University of KwaZulu-Natal in Pietermaritzburg, Professor $\mathrm{Agbu}^{6}$ has facilitated applications for aspiring students from Cameroon to undertake study opportunities in South Africa, even providing accommodation to some as they start a new life in South Africa. With the growing hostility and xenophobia directed at foreigners ${ }^{7}$, his home had become a sanctuary for Cameroonian migrants in Pietermaritzburg and they always organize family events connecting Cameroonians and providing networks for information sharing, caring for one another and maintaining contacts with families back home. Joshua and Lisa were raised in Pietermaritzburg, South Africa, after spending their childhood in Cameroon and as Zudidah et al. (2013: 1) observe, immigration is not only about changing countries, but it is also about shifting identities and this change is especially important for adolescents. The dynamics around shifting identities make the incorporation of

${ }^{5}$ The blessing of the marriage before they were legally married was a slight deviation from the normal procedure given the urgency that the prospective couple had to get married before travelling to Japan. Under normal circumstances, the Order of blessing of an existing marriage will require that they produce a marriage certificate. During the counselling sessions, this process was explained to the couple.

${ }^{6}$ Not his real name.

${ }^{7}$ For example, see Mpofu, B. 2019. Church as Hostile, Host or Home: Sociological and Theological Perspectives on Migration in Johannesburg, South Africa. Alternation. https://doi.org/10.29086/2519-5476/2018/sp22a6 


\section{Buhle Mpofu}

immigrants into host communities an arduous process as they have to integrate into new communities through challenging identity formation processes sometimes exposing them to risks and vulnerabilities (Schwartz et al. 2006).

I have observed the bi-acculturation (Arel 2014:10) trend among immigrant youth in South Africa, who are able to learn more than one culture or language as confirmed by Joshua below:

We are lucky because we both are Cameroonians even though we have spent most of our teenage years here in South Africa where we learned other cultures. So that will help us to get along and be supportive to each other while we are in Japan (Joshua, address to a congregation in Pietermaritzburg, SA).

Lisa and Joshua fall in the category of migrant children who came with their parents while they were young and had to learn a new culture while attending a school which is predominantly Zulu in Pietermaritzburg, South Africa. As Suarez (2008) rightly observed, migrant children have to endure the pressure and face tough choices as they construct new cultural identities in host countries. Although surrounded by Cameroonians at home and during social family times, Lisa and Joshua had to spend time at school and church where they were exposed to other cultures. The congregation they attended had migrants from many African countries, including India and South Korea. This culturally diverse community shaped Joshua and Lisa and they felt confident to go and start a new life in Japan as a new couple.

We are both Cameroonians and we think that will make our lives easy because we understand each other. (Joshua, during a counselling session on $13^{\text {th }}$ July 2019 , Pietermaritzburg).

\section{Dating}

Based on the experiences of Lisa and Joshua, it is clear that one of the areas where cultural practices and societal values are intently distinguishable between foreign migrants and local South Africans, is in their marital rites of passage and celebration of relationships or marriage rites and preparations. Although culturally, their celebration reflected Cameroonian practices and they were flexible to adapt to circumstances that had arisen, as opposed to very 
strict cultural practices among the local Zulu people. After the blessing of their marriage was conducted, circumstances leading to Joshua and Lisa's relocation plans were explained by a local elder:

They have been courting and they have an appointment with the Cameroonian embassy to marry before they leave for Japan ... (Local church elder).

And he made it clear that the couple still had a lot to learn, especially given that they were starting a new life, in a new cultural setting, something Joshua admitted:

We still have a lot to learn from each other because growing up in South Africa has influenced most of our childhood (Joshua, during a counselling session on $13^{\text {th }}$ July 2019 , Pietermaritzburg).

The institution of marriage and the cultural rites which accompany it often reflect the identity of people. Among the Zulu people, for example, the question ubuya kuphi? (where do you come from?) is popular and by asking where you come from, they refer to your cultural roots and origins so that they can create a perception aboutthe kind of a person that you are. This becomes a pre-judgement to one's character and it is stereotypical in-so-far as it adds unnecessary burden to migrants who are adapting to a new and often hybrid culture. With marriage at the centre - not just of religio-cultural practices - but also invoking socio-economic and legal migration formalities, matrimony becomes an area of consternation. Another example is the United States of America's (USA's) so-called 'green card' marriages, where there are crosscultural intersections which highlight the social and economic differences between migrants and among migrants and hosts. During the counselling sessions and church service, it was also interesting to observe that Joshua spoke most of the time while Lisa quietly nodded her head in agreement - something that has cultural connotations in relationships between men and women, especially within the Zulu culture. Indeed, these observations and other emerging themes are profound, such as how some young girls are being exposed to early marriages or even transactional relationships due to economic pressure placed on them by the prevailing circumstances surrounding their migrant experiences. However, this study was limited to practices which depict 


\section{Buhle Mpofu}

symbols and instruments deployed by young migrants as identity formation tools for belonging.

\section{Acculturation Lifestyles for Other Adolescents}

The following section highlights the experiences of three other young migrants who were interviewed between $26^{\text {th }}$ and $27^{\text {th }}$ July 2019 in Pietermaritzburg to demonstrate how adolescents develop new lifestyles through fashion and hairstyling practices, language/accent/naming, food cultures, religious association and music. It explores how they deploy them as instruments to adapt in new communities while simultaneously retaining their cultures from home countries. I am now moving from the marriage counselling and blessing of Lisa and Joshua to analyse data which emerged from brief interviews with Ruth, Nokubonga and Tasha. Starting with Ruth, each one had something significant to say in helping us appreciate how young migrants navigate cultural landscapes, as they make friends across cultures within the schooling and religious environment where they interact with their local peers:

South Africa is like, my home now because I never lived in Ghana although I have Ghanaian friends. I also have friends from Zimbabwe, Kenya and other countries, it's like .... I really don't know what I am .... (Ruth from Ghana).

Like Ruth, young migrants navigate cultural diversity through experiences that help them deal with identity crises in various ways. While Ruth's experience in Johannesburg gave her a sense of home, she also had to contend with the reality of living with her friends from Zimbabwe, Kenya and other countries. Yet, for Nokubonga, maintaining her identity revolved around fashion and hair-styling practices.

\section{Fashion and Hair Styling Practices}

As part of acculturation, fashion and hair styling plays a significant role in the lives of young people, as a means for identifying with locals and belonging. As Nokubonga stated below:

I love doing my braids the way I always did them in Zimbabwe but 
here they don't want me to do that style at school ... so I find that irritating because it takes away my freedom (Nokubonga, Pietermaritzburg).

Most migrant children and youth are clearly distinguishable from local hosts by the way they dress and do their hair, especially girls. According to Bennett (2009: 152) 'all bodies carry marks of their experience...Body appearance offers an initial orientation in many encounters, and hence supply the most obvious and widespread way of classifying people - by gender, race, age and class... What one wears continues to mark position, for example, skirt, dress, business shirt, shoes, chain, watches, and so on convey meaning' (Bennett 2009 in Dang 2016: 161). In a similar narrative, Lisa said:

I sometimes dress in Cameroonian style because I have learned this from my mom, but we are both fine because we understand our Cameroonian culture (Lisa, during a counselling session, Pietermaritzburg).

\section{Language, Accent and Naming}

During the interview with Lisa, she explained that there were times when she struggled to understand her peers. However, she noted that the use of the English language as a medium for communication eased the confusion.

Sometimes I don't understand the way they talk to me, they talk their language alone...but then we use English (Conversation with Tasha, from Ghana).

Language is an integral behavioural element for any culture and as Diller and others (2003) rightly observed, these behavioural experiences may include unsettling, as well as psychologically, socially, and religiously disconcerting encounters, which are often confusing to adolescents (Diler et al. 2003). Language becomes unsettling when migrants struggle to pronounce local words and as a result, they are labelled, as was the case with Tasha:

They Call us Kwerekweres and Me and My Friend don't like them ... (Tasha). 


\section{Buhle Mpofu}

Names are useful as they tell us more about places, cultures and different languages of the world (Godoi 2013). But naming can lead to disconcerting encounters, given that migrant children are easy to identify in KwaZulu-Natal Province, not just because they do not speak the local isiZulu language, but because their names and surnames are not Zulu and often not easy to pronounce among locals. For example, names became an important symbol in the novel of Chimamanda (2014) as Ifemelu, Obinze, and other characters work and study abroad in places where their names make them clear outsiders and sometimes even expose them dangerously in what could be considered 'illegal' practices, where they take local names for work and survival purposes. I know of a lady in Pietermaritzburg CBD from Harare, Zimbabwe who can hardly speak fluent isiZulu, but runs a food outlet called Sibo Take-Aways and her name is Sibongile, which is Zulu for 'we are grateful'. This name helps her to belong and identify with the Zulu locals but brings with is risks of exposure and the resultant consequences. These are some of the unsettling, as well as psychologically, socially disconcerting encounters for foreign migrants.

Just like in the novel, Americanah already cited, where the name Ifemelu must take on - Ngozi - and this is more significant in that it is one of the given names of the author - the adolescents in this study navigate their new cultural context by developing new lifestyles through fashion and hairstyling practices, language/accent/naming as means to explore new communities and identify with their peers. The significance of this observation is that within a restrictive environment where people must meticulously find ways of expressing their identity, borrowed names and even nicknames become an integral part of countering rejection and navigating the disconcerting cultural terrain.

\section{Food Cultures}

One of the distinguishing cultural features of the wedding ceremony for Lisa and Joshua was their Cameroonian food dishes. Like most migrants, Lisa and Joshua kept their identity through food choices. This is also a central theme providing a nexus in Adichie Chimamanda's reflections as she tells her personal story of searching for an American dream in the context of developing her identity and fostering a sense of belonging. According to Alemerico Gina (2014: 2), food studies is an emerging interdisciplinary field of study that examines the complex relationships between food, culture, and society, in nu- 
merous disciplines in the humanities and social sciences. She observes that:

Food studies looks at people's relationships with food and reveals an abundance of information about them. Food choices expose a group or a person's beliefs, passions, background knowledge, assumptions and personalities. Hauck-Lawson (2004) introduced the concept of food voice. She suggested that what one eats or chooses not to eat communicates aspects of a person's identity or emotion in a manner that words alone cannot. Food choices tell stories of families, migrations, assimilation, resistance, changes over times, and personal as well as group identity. So why do we need to study food in a nonepicurean manner? Food studies ... can help us understand ourselves and others better. It can help debunk stereotypes and promote acceptance across individuals and groups (Alemerico 2014: 3).

The significance of the above observation is reflected in Chimamanda's character, Ifemelu, when she is asked to order and eat Chinese food. She declined the offer of Chinese food and opted instead, for American food - a granola bar. This was a way to identify with locals. In South Africa there is a cliché, 'local is lekker', which means that whatever one engages in that is local is not only acceptable, but is also enjoyable and appreciated - it is pleasant, good, fine, amusing, delightful, pleasant, appealing, or just nice. Although names, language and some cultural practices will isolate local migrant youth, they often find a way to explore South African food 'habits' as a way to identify with locals. This was evident in the braai (barbecue) hosted for Joshua and Lisa at which popular South African boerewors ${ }^{8}$ was served, together with Cameroonian foods. According to Alemerico (2014:3), Kittler et al. (2012) coined the term 'food habits' to describe the manner in which humans use food, stating that the significance of the food habits process is that it is unique to human beings as they pondered why people spend so much time, energy, money and creativity on eating, as reflected through a familiar saying, 'you are what you eat'. For this study, a combination of boerewors and Cameroonian food dishes reflect bi-acculturation as a means for navigating cultural landscapes.

8 This is a popular type of traditional South African sausage, typically containing coarsely ground beef and pork seasoned with spices. 


\section{Music as a Symbol of Identity}

As part of acculturation, music plays a significant role in the lives of young people as a means for maintaining their identity and navigating for belonging in local communities. As the conversation with Nokubonga reflected:

Sometimes I miss my old friends in Zim, but I have made new friends here although they can't sing most of my songs and it sucks. But I can sing with them songs from Nasty C, Vusi Nova and others (Nokubonga, Pietermaritzburg).

Having attended a predominantly white school primary school, and now attending an all-black secondary school in Pietermaritzburg's CBD, Nokubonga has been unsettled as well as being psychologically and socially confused, as she navigates diverse cultural settings characterised by changes in race, class and nationality. These skewed intersections are candidly reflected through perverse musical exposure by peers. She expressed her frustration at her friends' failure to sing along to her Zimbabwean musical sensations. Although she had adapted to a more Western musical cultural style, singing along to Nasty $\mathrm{C}$ with her friends from a predominantly white primary school, moving to a predominantly black secondary school also demanded another shift, this time to local township music of the likes of Vusi Nova and others. Although Nokubonga is humorous about her frustrating musical encounters with her peers, her experiences symbolize an identity crisis and the ensuing racial divides of the South African society where blacks and whites have not fully integrated over decades despite the banning of apartheid.

In Chimamanda's novel, race is a central theme as she reflects on being a black woman in the USA. Chimamanda Ngozi uses her characters to show that it is easy to forget the marginalisation of black lives because of her characters, Adichie and Ifemelu's, parallel success through their writing in the story. By paying attention to this event, the author reminds her readers that even in the pop cultural sphere of magazines (and music in the South African context), the USA has a long way to go toward equal representation. Just like in South Africa, these perverse practices remain a problem which goes 'unnoticed' by many white people who decry 'reverse racism' when there are attempts to address the issue, through the creation of alternate spaces that promote equality and racial integration. For migrant youth, this uneven 
landscape results in ambivalence of identity and belonging, as result they survive through insidious navigation within an anti-immigrant and hostile society. These revelations are profound as they highlight the significant role of music, not just as a symbol for nation building, but also as an integral part in the integration of new arrivals.

\section{Religious Association}

Religious association is one of the key elements of acculturation among migrants. Religious practices, values and even dressing can provide means for belonging and identifying with communities. This was clearly visible in the observation by Nokubonga who asked:

Why do those girls cover their heads like their mothers? Is it because of their church? (Nokubonga, after seeing a Muslim child in town).

Religious freedom of association often reflects diversity of any society, and this is one area in which the diversity of South African communities is visible. In a paper exploring the Limits of Social Responsibility with respect to Religion and Migration in South Africa (Mpofu \& Settler 2017) we highlighted the interface between religion and migration, observing that scholars like Spickard and Adogame (2010) point to the instrumentalist uses of religion in the context of migration, while others are concerned with new migrants' use of churches and mosques as the primary site for building social networks (Robertson 2012). We observed how other scholars depict religion as a resource for migrants and source of resilience to help them cope with the challenges experienced during migration (Hagan \& Ebaugh 2003), and how migrants replicate religious traditions at various sites of settlement as an assertion of cultural and religious identity (Levitt 2000; 2007; Huwelmeier \& Krause 2010). This paper is concerned with how religion is an important and often positive component in developing a sense of belonging and identity for people on the move.

While Nokubonga could not understand why a Muslim child should cover her head, this shows the confusion resulting from cultural or religious diversity. However, religion can provide a framework for values, a sense of belonging and direction as migrants navigate the new communities in which they find themselves. By asking the above question, 'why do girls cover their 


\section{Buhle Mpofu}

heads like their mothers?' the young Nokubonga was struggling to come to terms with the diverse religious identities within her new community; such a struggle reflects an identification crisis and a search for belonging. Although she did not see her opportunities for belonging within the Christian communities, Nokubonga did not seem to realize that religious identity helps young migrants to relate with peers who readily identify with and accept them. For Nokubonga, forces from her multi-racial primary school, black African communities and Christian communities colluded to cast a shadow on her identity. This is one symbolic example of conflicting experiences of religiocultural identity for second generation Africans in the diaspora. Alluding to this dilemma, Suarez (2008) observes that '[a] crucial part of adolescence is a search for identity. Many adolescents have to endure the pressure within and outside of their host communities and face tough choices as they construct intercultural identities' (Suarez 2008: 10).

Findings from this study demonstrate how second-generation African adolescents navigate changing cultural landscapes to craft new lifestyles as a way of belonging within the South African communities. By adopting the bicultural acculturation approach as hybridity of the new and continuous identity formation for immigrants, the paper highlighted that wherein scholars have identified various options for identity formation, migrants and their children in Pietermaritzburg, South Africa, tend to exchange values with each other and host communities. In doing so, they draw from their cultural backgrounds to deploy embodied symbols/artefacts such as fashion and hairstyling practices, language/accent/naming, food cultures, and religious association and music as instruments to adapt within new communities, while simultaneously retaining their cultures from home countries.

\section{Conclusions and Recommendations}

This case study demonstrates that the impact of changing cultural landscapes on migrant adolescents' identity is reflected in their agency in navigating new cultural contexts by developing and adapting to new lifestyles through components of cultural capital, namely skills, competency, and the new personal qualities, fashion, hairstyling practices, language/accents and naming as means to survive and explore host communities. In doing so, they strive to identify with their local peers while maintaining their homeland cultural practices. Another significant observation was that- within a restrictive 
environment where people must meticulously find ways of expressing their identity - borrowed names and even nicknames become an integral part of countering rejection and navigating the disconcerting cultural terrain. Further studies are needed to closely examine the legal and ethical implications of using borrowed names within the context of survival strategies employed by migrants.

Given the circumstances of Lisa and Joshua within a religious community, the study also demonstrated that religious institutions are well placed to provide counselling and support to migrant young adults preparing for marriages, especially if they have to [e]migrate. For Joshua and Lisa, spending time during courtship in a congregation in Pietermaritzburg, afforded them an opportunity to get to know each other before they started a new life in a different cultural setting in Japan. They may have acculturated differently, but sharing a life together in a new Japanese environment will help them cope with their new circumstances. Therefore, pastoral guidance and accompanyment are necessary in assisting adolescent migrants to navigate new cultural landscapes and pre-marital counselling should be considered as part of rites of passage to adulthood in the absence of traditional family structures.

South Africa is a nation still struggling with issues on race and identity. This has been evident in recent debates on what it is to be a 'rainbow nation' after it was assumed that the Truth and Reconciliation Commission (TRC) had facilitated a hearing process which dealt with the racial divides and suffering experienced during the apartheid era. These new debates should incorporate everyone, in particular the presence of foreign migrants should be taken seriously in attempts to re-define South African values, nationality and citizenship. There is a need to further examine categories of acculturation given that immigrants are part of marginalised communities despite their willingness learn new things and contribute to nation building. They do this through transnational socio-economic activities spanning through different spaces. On the contrary, local South Africans remain focused on locally situated cultural practices, living a blind-folded life of single, racially and culturally isolated lifestyles which create stereotypes in the minds of people who know only one story of life, something Chimamanda warns and identifies as dangerous ${ }^{9}$.

${ }^{9}$ Chimamanda 2009. The Danger of a single Story. Video available at: https://www.ted.com/talks/chimamanda_adichie_the_danger_of_a_single_sto ry?language=en (Accessed on 03 September 2019.) 
While the situation of growing intolerance towards foreign migrants presents many challenges, it also offers great opportunities for learning. South African communities need to embrace multi-culturalism as opposed to failed rainbowism which currently places emphasis on Zulu, Xhosa, Sotho, Afrikaner and English cultures. In addition, these cultures enjoy a privileged status of dominance while other sub-cultures, languages, ethnicities and tribal/ indigenous groups are isolated. This should change.

Lastly, it should be stated that despite a growing scholarly interest in child migration studies within the field of social sciences, much of this literature has focused on children and youth from the Global North and more data still needs to be collected to inform policy developments in the Global South. Therefore, this article is a contribution toward contextually based research on identity and child migration as it reflects not only the hopes and aspirations, but also the stresses and strains of migratory experiences of migrant children and youth in South Africa.

\section{References}

Alemerico, G.M. 2014. Food and Identity: Food Studies, Cultural, and Personal Identity. Journal of International Business and Cultural Studies 1.

Adogame, A. \& J. Spikard 2010. Religion Crossing Boundaries: Transnational Religious and Social Dynamics in Africa and the New African Diaspora. Leiden: Brill.

https://doi.org/10.1163/ej.9789004187306.i-280

Arel, S.K. 2014. Ethnic Identity in Children of Immigrants: Identity Pathways, Academic Outcomes, and the Mediating Effect of Parents and Peers. A $\mathrm{PhD}$ Dissertation (Education and Psychology). University of Michigan.

Asis, M.M.B. 2006. Living with Migration: Experiences of Left-behind Children in the Philippines. Asian Population Studies 2,1: 45 - 67. https://doi.org/10.1080/17441730600700556

Battistella, G. \& M.C.G. Conaco 1998. The Impact of Labour Migration on Children Left behind: A Study of Elementary School Children in the Philippines. Sojourn: Journal of Social Issues in Southeast Asia 13,2: 220 $-241$.

https://doi.org/10.1355/SJ13-2C 
Bennett, T. 2009. Culture, Class, Distinction. Abingdon, Oxon; New York, NY: Routledge. https://doi.org/10.4324/9780203930571

Bhabha, J. \& S. Schmidt 2008. Seeking Asylum Alone: Unaccompanied and Separated Children and Refugee Protection in the U.S. Journal of the History of Childhood and Youth 1,1: 127 - 138.

https://doi.org/10.1353/hcy.2008.0007

Chimamanda A.N. 2014. Americanah. New York: Anchor Books.

Dang, T.T. 2016. Understanding the Lived Experiences and Identities of Young Rural to Urban Migrant Workers in Vietnam. Thesis in Community Development BA submitted for the degree of Doctor of Philosophy at the University of Queensland in School of Social Science.

Diler, R.S. A. Avci \& G. Seydaoglu 2003. Emotional and Behavioural Problems in Migrant Children. Swiss Medical Weekly 133,1/2: 16 - 21.

Fillippa, O.M., E.M. Cronje \& I. Ferns 2013. Left Behind: A Qualitative Study of Zimbabwean Adolescents Affected by Parental Migration. PINS 52: 36 $-52$.

Godoi, D. 2013. The Importance of Language in Society, Chapter 1. Available at:

https://shodhganga.inflibnet.ac.in/bitstream/10603/29223/17/9_chapter\% 201.pdf (Accessed on 09 July 2019.)

Global Migration Group (GMG) 2013. Exploitation and Abuse of International Migrants, Particularly those in an Irregular Situation: A Human Rights Approach THEMATIC PAPER.

https://www.unodc.org/documents/humantrafficking/2013/2013_GMG_Thematic_Paper.pdf (Accessed on 24 August 2019.)

Graham, E. \& L. Jordan 2011. Migrant Parents and the Psychological Wellbeing of Left Behind Children in South-East Asia. Journal of Marriage and Family 73,4: 763 - 787.

https://doi.org/10.1111/j.1741-3737.2011.00844.x

PMid:22163371 PMCid:PMC3229683

Hagan, J. \& H.R. Ebaugh 2003. Calling upon the Sacred: Migrants' Use of Religion in the Migration Process. International Migration Review 37,4. https://doi.org/10.1111/j.1747-7379.2003.tb00173.x

Huwelmeier, G. \& K. Krause (eds.). 2010. Traveling Spirits: Migrants, Markets, Mobilities. New York \& London: Routledge.

https://doi.org/10.4324/9780203865262 
Huijsmans, R. 2015. Children and Young People in Migration: A Relational Approach. In Ní Laoire, C., A. White, T. Skelton (eds.): Geographies of Children and Young People Movement, Mobilities and Journeys. Volume 6. Cham: Springer.

https://doi.org/10.1007/978-981-4585-93-4_1-1

Hong, Y.Y., M. Morris, C.Y. Chiu \& V. Benet 2000. Multicultural Minds: A Dynamic Constructivist Approach to Culture and Cognition. The American Psychologist 55:709 - 720.

https://doi/10.1037/0003-066X.55.7.709

Idemudia, E.S., J.K. Williams \& G.E. Wyatt 2013. Migration Challenges among Zimbabwean Refugees before, during and Post Arrival in South Africa. Journal of Injury \& Violence Research 5,1: 17 - 27.

https://doi/10.5249/jivr.v5i1.185

PMid:22095004 PMCid:PMC3591728

Jokhan, M. 2008. Parental Absence as a Consequence of Migration: Reviewing the Literature. Social and Economic Studies 57,2: 89 - 117.

http://www.jstor.org/stable/27866552

Kittler, P.G., K.P. Sucher \& M.N. Nelms 2012. Food and Culture. $6^{\text {th }}$ Edition. Belmont, CA: Wadsworth.

Kubo, A. \& J. van Niekerk 2008. Child Trafficking in Southern Africa. Global Alliance against Traffic in Women 33 - 35.

Levitt, P. 2007. God Needs no Passport. New York: The New Press.

Levitt, P. 2001. Between God, Ethnicity and Country: An Approach to the Study of Transnational Religion. Paper presented at Workshop on Transnational Migration: Comparative Perspectives, 30 June - 01 July 2001, Princeton University.

Mpofu, B. \& F. Settler 2017. The Limits of Social Responsibility with Respect to Religion and Migration in South Africa. Journal for the Study of Religion 30, 2:12 - 31.

https://doi.org/10.17159/2413-3027/2017/v30n2a1

Mpofu, B. 2018. Church as Hostile, Host or Home: Sociological and Theological Perspectives on Migration in Johannesburg, South Africa. Alternation Special Edition 22: 103 - 118.

https://doi.org/10.29086/2519-5476/2018/sp22a6

Palmary, I. 2009. For Better Implementation of Migrant Children's Rights in South Africa. UNICEF.

https://www.unicef.org/southafrica/SAF_resources_migrantchild1.pdf. 
Policy Action Network (PAN) 2014. Unaccompanied Foreign Migrant Children in South Africa Fact Sheet.

https://children.pan.org.za/sites/default/files/publicationdocuments/Unac companied\%20Foreign\%20Migrant\%20Children\%20Fact\%20Sheet.pdf.

Suarez, O. 2008. Stories of Identity Religion, Migration, and Belonging in a

Changing World. U.S.: Facing History and Ourselves Publication.

Schwartz, S.J., M.J. Montgomery \& E. Briones 2006. The Role of Identity in Acculturation among Immigrant People: Theoretical Propositions, Empirical Questions, and Applied Recommendations. Human Development 49: 1 - 30. https://doi.org/10.1159/000090300

Scholz, R.W. \& O. Tietje 2002. Embedded Case Study Methods: Integrating Quantitative and Qualitative Knowledge. London: Sage Publications Inc.

Scholz, R.W. \& C.R. Binder 2011. Environmental Literacy in Science and

Society: From Knowledge to Decisions. Cambridge: Cambridge University Press. https://doi.org/10.1017/CBO9780511921520

Shah, S. 2004. The Story Teller's Daughter: One Woman's Return to her Lost Homeland. London: Anchor Publishing

Sloth-Nielsen, J. \& M. Ackermann 2016. Unaccompanied and Separated Foreign Children in the Care System in the Western Cape - A Socio-Legal Study. Potchefstroom Electronic Law Journal/19,1.

https://doi.org/10.17159/1727-3781/2016/v19i0a1207

Tawodzera, M.C. \& M. Themane 2019. Schooling Experiences of Children Left behind in Zimbabwe by Emigrating Parents: Implications for Inclusive Education. South African Journal of Education 39, Supplement 1: s1s13. https://doi.org/10.15700/saje.v39ns1a1797

The Guardian. Available at: https://www.theguardian.com/usnews/2019/jun/25/they-wanted-the- american-dream-reporter-revealsstory-behind-tragic-photo (Accessed on 27 June 2019.)

Trew, J.D. 2009. Migration in Childhood and its Impact on National Identity Construction among Migrants from Northern Ireland. Irish Studies Review 17,3: 297 - 314. https://doi.org/10.1080/09670880903115512

Toppelberg, C.O. \& B.A. Collins 2010. Language, Culture, and Adaptation in Immigrant Children. Child and Adolescent Psychiatric Clinics of North America 19,4: 697 - 717. https://doi.org/10.1016/j.chc.2010.07.003

PMid:21056342 PMCid:PMC3526379

International Organisation for Migration (IOM) 2010. A Framework and Recommendations for Action on Children Affected by Migration in the 
Caribbean.

https://www.unicef.org/easterncaribbean/A Framework and Recomme ndations for Actions on Children Affected by Migration.pdf (Accessed 05 May 2019.)

United Nations High Commissioner for Refugees UNHCR 1994. Refugee

Children: Guidelines on Protection and Care. Available at: https://www.unhcr.org/3b84c6c67.pdf.

United Nations (UN) 2016. 244 Million International Migrants Living Abroad Worldwide, New UN Statistics Reveal. (Accessed on 24 August 2019.)

https://www.un.org/sustainabledevelopment/blog/2016/01/244-millioninternational-migrants-living-abroad-worldwide-new-un-statisticsreveal/

Yaqub S. 2009. Child Migrants with and without Parents: Census-based Estimates of Scale and Characteristics in Argentina, Chile and South Africa, IDP No. 2009-02. Florence: UNICEF /Innocenti Research Centre. Yin, R.K. 2003. Case Study Research, Design and Methods. $3^{\text {rd }}$ Edition. Newbury Park: Sage Publications.

Dr. Buhle Mpofu Lecturer in Religion and Mission Studies Faculty of Theology and Religion University of Pretoria Pretoria buhlem202@yahoo.co.uk 